\title{
THE EFFECTS OF RECREATION THERAPY ON THE HABIT OF SMOKING AND POSITIVE-NEGATIVE SYMPTOMS AMONG PATIENTS WITH CHRONIC SCHIZOPHRENIA
}

\author{
M. G. Pirbalouti', A. Shariat ${ }^{1}$, A. Ghazanfari', Y. Sh. Naghani ${ }^{1}$, N. G. Kamaliyeh ${ }^{2}$ \\ 1Department of Psychology, Faculty of Humanities, Shahrekord Branch, Islamic Azad University - Shahrekord, Iran \\ ${ }^{2}$ Department of Resource Management and Consumer Studies, Faculty of Human Ecology, University Putra \\ - Malaysia, Malaysia
}

\begin{abstract}
Schizophrenia is a psychiatric condition that has detrimental outcomes on an individual's thinking, understanding and feelings. However, it not only affects one's actions and emotions, but also, and quite specifically, creates an avenue for such antisocial behavior as seclusion. Hence, it is important to highlight the necessary requirements for the recovery of schizophrenic patients and subsequently delve deeper into the signs and symptoms of schizophrenia itself, especially among patients who have been confined to psychiatric care for too long. The aim of this study was to determine the effects of recreation therapy on smoking as well as the positive-negative symptoms of schizophrenia among patients who have reached the chronic stage of this condition. Essentially, this was a semi-experimental study with one pretest and one posttest. 50 patients under psychiatric care, aged between 30 to 50 years, were selected and then equally divided into the control and experimental groups. The instruments for this research were the Anderson questionnaire and the smoking cigarette questionnaire, the latter being created by the researcher. Data were analyzed using descriptive and inferential statistics. To evaluate the hypothesis of research, this study relied on a covariance analysis. Based on the results, it can be said that there were significant $(p \leq 0.05)$ differences between the control and experimental groups related to smoking as well as the positive-negative symptoms of schizophrenia. It shows that 4 months of recreation therapy was able to decrease the prevalence of smoking (19.9\%), in addition to the positive symptoms (18.3\%) and negative symptoms (14.7\%) of schizophrenia within the experimental group. It is hoped that the results of this study will encourage the use of recreation therapy as a practical and non-pharmacological form of treatment for patients with chronic schizophrenia.
\end{abstract}

Key words: schizophrenia; recreation therapy; signs and symptoms; smoking

Corresponding author: A. Shariat, Department of Psychology, Faculty of Humanities, Shahrekord Branch, Islamic Azad University, Shahrekord, Iran, e-mail: ashariat2013@gmail.com

\section{INTRODUCTION}

chizophrenia is a severe mental disorder that affects humans in young adulthood, often leading to lifelong disability and posing an enormous burden for those who are afflicted as well as their loved ones [1]. Schizophrenia with a ranking of 11th has been identified as a main concern of public health that promotes a damaging lifestyle [2], affecting more than 21 million people worldwide (WHO, 
2015 ) with a prevalence of $0.7-1 \%$ [3], among youths [4]. It is a complex mental disorder characterized by sets of positive, negative, and cognitive deficit symptoms in the areas of attention, memory, and executive functioning [5]. In schizophrenia, distinct impairments are experienced in important functioning areas such as work, interpersonal relations, and self-care. Such impairments prevent patients from developing social relationships, fulfilling their social roles or meeting their social needs, resulting in a decrease in their quality of life [6]. Early detection and treatment is critical because, if left untreated, schizophrenia, or any form of mental illness for that matter, has significant negative consequences for academic achievement [7, 8], employment [9], substance misuse [10] and social relationships [11]. In the treatment of schizophrenia, pharmacologic approaches and psychosocial interventions are supplementary of each other [12]. Although medications are effective in reducing evident positive symptoms and relapses, they are not so effective in helping patients acquire social functioning and independent living skills [13]. For this reason, psychological treatments on an individual, family, or group basis in pharmacotherapy is included to reduce relapses of the aforesaid condition [14] and increases the success of patients in coping with their predicament and subsequently in achieving their life goals [6, 11]. Rehabilitation programs can help a person recover the confidence and skills needed to live a productive and independent life in the community [15]. Smoking, on the other hand, is rampant among schizophrenic patients, and this is associated with an additional concern: it induces the metabolism of olanzapine and clozapine, thereby reducing the chances of benefitting from standard doses of these drugs [5]. The current study aimed to assess the effects of recreational therapy on the habit of smoking among schizophrenic patients as well as the positive-negative symptoms of schizophrenia itself.

\section{MATERIAL AND METHODS}

The current study was a semi-experimental study with one pretest and one post-test. Among the 70 patients who were diagnosed with schizophrenia and were placed under medical treatment at a Psychiatry hospital, 50 of them, aged between 30-50 years, have been selected for this study. These patients, who have also had a habit of cigarette-smoking, were then divided into the control and experimental groups. The demographic information of the patients, including age, gender, duration of disease and type of medication was collected prior to treatment [16]. The questionnaire was also completed through a family member and under observation from the pa- tient's psychologist before and after a 4-month recreational intervention. The instruments used in this research were the PANSS questionnaire as well as the smoking cigarette questionnaire created by the researcher. An informed consent form was signed by the families of participating patients in line with the Helsinki Declaration's ethical guidelines referring to the use of human participants in medical studies [17, 18]. This research was confirmed by the Institutional Review Board of the Department of Psychology at Shahrekord University.

\section{Instruments}

The questionnaire used in this study included seven questions regarding the sociodemographic characteristics (age, gender, marital status, education level, and employment status) and disease-related characteristics (duration of the disease and number of hospitalizations) of the patients.

\section{Positive and negative syndrome scale (PANSS)}

This scale is a medical scale used for measuring symptom severity of patients with schizophrenia. It was published in 1987 by Stanley Kay [19] and widely used in the study of antipsychotic therapy. The scale consists of five subscales and 30 items, 7-point rating instrument that has adapted 18 items from the Brief Psychiatric Rating Scale (BPRS) [20] and 12 items from the Psychopathology Rating Schedule (PRS) [21]. Each item on the PANSS questionnaire is accompanied by a complete definition as well as detailed anchoring criteria for all seven rating points, which represent increasing levels of psychopathology: 1 = absent, $2=$ minimal, $3=$ mild, $4=$ moderate, $5=$ moderate-severe, $6=$ severe, and $7=$ extreme. The total score is obtained by adding the subscale scores together [22]. The scale's alpha coefficient is 0.87 and, in this study, the alpha coefficient of the scale was found to be 0.89 .

\section{Smoking cigarette questionnaire}

This scale was designed by the researcher, and it contains 10 questions with 5 Likert scales that assess the prevalence of smoking among patients. The reliability of this questionnaire for both the control and experimental groups was at .802 and .765 , respectively. In order to assess the validity of this questionnaire, it was distributed among 30 of the patients who were able to answer it.

\section{Intervention}

The intervention for this study included a series of walking, group singing, camping for breakfast, listening to music, painting, watering plants, tailoring, ropejumping, volleyball and table tennis, 6 times a week, with each session at 2 hours long (Table 1). 
Table 1. Protocol of recreation therapy

\begin{tabular}{|l|l|l|}
\hline Activity sessions & Time & Activity \\
\hline Saturday-Tuesday & $7-9$ & $\begin{array}{l}\text { Walking, singing in group, } \\
\text { camping for breakfast, listening } \\
\text { music }\end{array}$ \\
\hline Sunday-Wednesday & $7-9$ & $\begin{array}{l}\text { Painting, music, watering } \\
\text { plants, tailoring }\end{array}$ \\
\hline Monday-Thursday & $7-9$ & $\begin{array}{l}\text { Rope jumping, volleyball and } \\
\text { table tennis }\end{array}$ \\
\hline
\end{tabular}

\section{Data analysis}

Prior to data analysis, the collected data was subjected to a normality test using the Kolmogorov-Smirnov test and results indicated that data was normally distributed $(p>.05)$. Levene's test was then used to test the homogeneity of variance. Results from the aforesaid test showed that variances were equal across both groups. To evaluate the hypothesis of the analysis, (ANCOVA) was used, while the pretest scores were used as covariate.

\section{RESULTS}

The results of this study showed that 4 months of recreation therapy was able to decrease the prevalence of smoking (19.9\%), in addition to the positive symptoms (18.3\%), and negative symptoms (14.7\%) of schizophrenia in the experimental group (Table 2).

Table 2. Mean and standard deviation (mean \pm SD)

\begin{tabular}{|c|c|c|c|}
\hline Variable & Group & $\begin{array}{c}\text { Pre test } \\
(\text { mean } \pm S D)\end{array}$ & $\begin{array}{c}\text { Post test } \\
\text { (mean } \pm \text { SD) }\end{array}$ \\
\hline \multirow{2}{*}{$\begin{array}{l}\text { Positive symp- } \\
\text { toms }\end{array}$} & Control & $98.48(11.4)$ & $98.32(11.18)$ \\
\hline & Expeirment & 83.21 (16.32) & 78.43 (16.29) \\
\hline \multirow{2}{*}{$\begin{array}{l}\text { Negative symp- } \\
\text { toms }\end{array}$} & Control & $72.08(9.6)$ & $71.24(9.76)$ \\
\hline & Expeirment & $58.04(9.25)$ & $54.84(8.35)$ \\
\hline \multirow{2}{*}{ Smoking } & Control & $37.48(7.82)$ & $37.92(7.59)$ \\
\hline & Expeirment & $32.48(6.61)$ & $29.84(6.38)$ \\
\hline
\end{tabular}

The findings of the analysis showed that there was a significant difference in the level of positive symptoms between both control and experimental groups $(F=10.092, p=<.05, h 2=0.183)$. It specifically showed that the intervention decreased patients' positive symptoms of schizophrenia. The results for negative symptoms also indicated a significant difference between the control and experimental groups $(\mathrm{F}=8.119, \mathrm{p}=<.05, \mathrm{~h} 2=0.147)$. The significant difference between both groups, in which there was a resulting decrease in patients' negative symptoms of schizophrenia. Similarly, the findings of the analysis showed that there was a significant difference in the prevalence of smoking cigarettes between both control and experimental groups $(F=11.679, p=<$ $.05, \mathrm{~h} 2=0.199)$. Specifically, findings showed that the intervention decreased patients' level of smoking (Table 3).

Table 3. Summary of ANCOVA for research variables

\begin{tabular}{|l|c|c|c|c|c|}
\hline Variable & Source & MS & $\mathbf{F}$ & $\mathbf{p}$ value & $\begin{array}{c}\text { Partial } \\
\text { Eta } \\
\text { Squared }\end{array}$ \\
\hline $\begin{array}{l}\text { Positive } \\
\text { symptoms }\end{array}$ & Pre test & $7,321.228$ & 216.481 & $<0.001$ & 0.828 \\
\cline { 2 - 6 } & Group & 341.304 & 10.092 & 0.003 & 0.183 \\
\hline $\begin{array}{l}\text { Negative } \\
\text { symptoms }\end{array}$ & Pre test & $2,839.396$ & 118.885 & $<0.001$ & 0.717 \\
\cline { 2 - 6 } & Group & 193.903 & 8.119 & 0.006 & 0.147 \\
\hline \multirow{2}{*}{ Smoking } & Pre test & $1,868.929$ & 177.716 & $<0.001$ & 0.791 \\
\cline { 2 - 6 } & Group & 122.816 & 11.679 & 0.001 & 0.199 \\
\hline
\end{tabular}

\section{DISCUSSION}

According to the present study that focused on the examination of recreational therapy as an effective and efficient method of treatment for schizophrenia as well as on creating social learning environments, it can be said that the engaging of patients in various healthy and leisurely activities is one of the influential factors affecting the effectiveness of their treatment. It can also result in the reduction of both positive and negative factors as well as the rampancy of smoking among patients with chronic schizophrenia. In addition, patients have displayed mental relaxation and a boost in self-confidence while engaging in said activities with their family members amidst a jovial atmosphere, even more so when they (the patients) have sufficient knowledge of, or prior experience in some of those activities. Alterman [23], in a previous study on drug use among schizophrenic patients, stated that since the increase of drug use results in increased severity of symptoms and repeated admissions as well as the spread of infectious diseases and rise in violence, crime, homelessness and lack of medication. All these eventually culminate into poor responses to drug therapy and deterioration in mental health as well as the creation of heavy emotional burdens for the patients and their families. Therefore, it is necessary to delve deeper into the issue of drug use among schizophrenic patients. Another study by Moore et al. [24] showed that the use of 
aerobic exercise and recreational therapy programs had the ability to prevent or reduce the problems and needs of these patients and subsequently increased their chances of social reintegration. Garcia et al., [25] posited that recreation and the community play a role in enhancing the daily functioning of patients with schizophrenia, whereas Garrido et al., [26] stated that to improve the quality of life in patients with schizophrenia, active treatment for negative symptoms, psychological distress and resistance should be recommended. In addition, Gallagher et al., [8] have asserted in their study that since CBT includes elements of cognitive rehabilitation therapy, it is considered an effective cure alongside drug therapy in the treatment of schizophrenic patients, and can thus be applied as an effective intervention for schizophrenic patients in Iran.

In this regard, Paquin et al., [27] in their study posited that compared to social stimulation, socio-cognitive training with the help of family members can improve the quality of life, social functioning and social cognitive skills of schizophrenic patients. Since schizophrenia is a mental disorder that requires rehabilitation, the treatment of its victims has enormous implications that are evident in the extent of its positive and negative symptoms. Also, considering the fact that schizophrenia severely affects patients and impairs their performances in various areas, it is therefore recommended that rehabilitation programs, including recreational therapy, be implemented on them, particularly in institutions of mental health. Apart from that, given that schizophrenia can be an important factor in the prevalence of smoking among its victims, specific programs to reduce smoking among schizophrenic patients should be considered as well. This is because these programs are indirectly significant in resolving the positive and negative symptoms of schizophrenia, in addition to the enhancement of good health and optimism. According to the results of the above study in this research, recreation therapy was considered as a cure and a useful method for functional and non-externalized hostile feelings and emotions. As such, it was also an effective way to curb the habit of smoking and signs of positive-negative chronic schizophrenia.

\section{CONCLUSION}

Based on the findings of this study and the significant effects of recreation therapy on rate of smoking as well as the positive-negative symptoms of schizophrenia among chronic patients, it is suggested that recreation therapy be used as a practical, cost-efficient and non-pharmacological treatment for patients suffering from chronic schizophrenia.

\section{REFERENCES}

1. Murray CJL, Lopez AD. Evidence-based health policy--lessons from the Global Burden of Disease Study. Science. 1996;274(5288):740-51.

2. Vos T, Barber RM, Bell B, Bertozzi-Villa A et al. Global, regional, and national incidence, prevalence, and years lived with disability for 301 acute and chronic diseases and injuries in 188 countries, 1990-2013: a systematic analysis for the Global Burden of Disease Study 2013. The Lancet. 2015;386(9995):743-51.

3. McGrath J, Saha S, Chant D, Welham J. Schizophrenia: a concise overview of incidence, prevalence, and mortality. Epidemiologic reviews. 2008;30(1):67-76.

4. Kendler KS, Gallagher TJ, Abelson JM, Kessler RC. Lifetime prevalence, demographic risk factors, and diagnostic validity of nonaffective psychosis as assessed in a US community sample: the National Comorbidity Survey. Archives of general psychiatry. 1996;53(11):1022-31.

5. Andrade C. Schizophrenia and smoking. Journal Clin. Psychiatry. 2012;73(6):725-7.

6. Yildiz M, Veznedaroglu B, Eryavuz A, Kayahan B. Psychosocial skills training on social functioning and quality of life in the treatment of schizophrenia: A controlled study in Turkey. International journal of psychiatry in clinical practice. 2004;8(4):219-25.

7. Kessler RC, Walters EE, Forthofer MS. The social consequences of psychiatric disorders, III: probability of marital stability. American Journal of Psychiatry. 1998;155(8):1092-6.

8. Gallagher M, McLeod HJ, McMillan TM. A systematic review of recommended modifications of CBT for people with cognitive impairments following brain injury. Neuropsychological rehabilitation. 2016;1-21.

9. Ettner SL, Frank RG, Kessler RC. The impact of psychiatric disorders on labor market outcomes. Industrial \& Labor Relations Review. 1997;51(1):64-81.

10. Weitzman ER. Poor mental health, depression, and associations with alcohol consumption, harm, and abuse in a national sample of young adults in college. The Journal of nervous and mental disease. 2004;192(4):269-77.

11. Brissos S, Pereira G, Balanzá-Martinez V. Quality of Life, Cognition, and Social Cognition in Schizophrenia. In: Beyond Assessment of Quality of Life in Schizophrenia. Springer; 2016. p. 25-51.

12. Yııdııım A, Hacıhasanoğlu Aşılar R, Camcıoğlu TH, Erdiman $S$, Karaağaç E. Effect of psychosocial skills training on disease symptoms, insight, internalized stigmatization, and social functioning in patients with schizophrenia. Rehabilitation Nursing. 2015;40(6):341-8.

13. Walton JA. Schizophrenia and life in the world of others. Canadian Journal of Nursing Research Archive. 2016;32(3):123-36.

14. Awad AG, Voruganti LNP. Issues That Slowed Progress in Assessments of Health-Related Quality of Life in Schizophrenia. In: Beyond Assessment of Quality of Life in Schizophrenia. Springer; 2016. p. 15-24.

15. Shariat A, Shariat A, Abedi A, Tamrin SBM. Physical activity as a prescription for the children with cerebral palsy. Russian Open Medical Journal. 2014;3(1):14-8. 
16. Jabarouti R, Shariat A, Shariat A. Effect of Persian Classic Poetry on the Level of Stress Hormone in Retired Academicians. Poetry thrapy. 2014;27(1):1-9.

17. Shariat A, Shariat A, Abedi A, Bahri STM. Physical activity as a prescription for the children with cerebral plasy. Russian Open Medical Journal. 2014;3:0108.

18. Shariat A, Kargarfard M, Sharifi GR. The effect of heavy resistance exercise on circadian rhythm of salivary cortisol in male body building athletes. Journal of isfahan medical school (IUMS). 2012;29(167):2400-14.

19. Kay SR, Flszbein A, Opfer LA. The positive and negative syndrome scale (PANSS) for schizophrenia. Schizophrenia bulletin. 1987;13(2):261-74.

20. Overall JE, Beller SA. The Brief Psychiatric Rating Scale (BPRS) in geropsychiatric research: I. Factor structure on an inpatient unit. Journal of Gerontology. 1984;39(2):187-93.

21. Kay SR, Opler LA, Fiszbein A. Significance of positive and negative syndromes in chronic schizophrenia. The British Journal of Psychiatry. 1986;149(4):439-48.
22. Aydemir Ö, Köroğlu E. Psikiyatride Kullanılan Klinik Ölçekler. 3'üncü baskı. Ankara Hekimler Yayın Birliği. 2007;346-53.

23. Alterman A. Substance abuse and psychopathology. Springer; 2014.

24. Moore G, Durstine JL, Painter P, Medicine AC of S. ACSM's Exercise Management for Persons With Chronic Diseases and Disabilities, 4E. Human Kinetics; 2016.

25. Garcia R, Flores ES, Chang SM. Healthy children, healthy communities: Schools, parks, recreation, and sustainable regional planning. Fordham Urb LJ. 2003;31(3):1267-76.

26. Garrido G, Barrios M, Penadés R, Enríquez M, Garolera M, Aragay N, Pajares M, Vallès V, Delgado L, Alberni J. Computer-assisted cognitive remediation therapy: cognition, selfesteem and quality of life in schizophrenia. Schizophrenia research. 2013;150(2):563-9.

27. Paquin K, Wilson AL, Cellard C et al. A systematic review on improving cognition in schizophrenia: which is the more commonly used type of training, practice or strategy learning? BMC psychiatry. 2014;14(1):139-44. 